\title{
Association of Morphological Characteristics of Palatal Rugae Pattern with Dental Malocclusion in Himachal Population
}

\author{
Indu Dhiman ${ }^{1}$, Shikha Thakur ${ }^{2}$, Depinder Pal Singh ${ }^{3}$, Tushar Abrol ${ }^{3}$ \\ ${ }^{1}$ Reader, ${ }^{2}$ Senior Lecturer, ${ }^{3}$ Former PG Student, \\ Department of Orthodontics and Dentofacial Orthopaedics, Himachal Dental College Sundernagar, \\ Himachal Pradesh \\ Corresponding Author: Shikha Thakur
}

\begin{abstract}
Introduction: Palatal rugae used for the evaluation of dental movements and as a landmark in the superimposition of dental cast for orthodontic purpose as it is a stable point. So, the aims and objectives of our study is to investigate the association of morphological characteristics of palatal rugae with dental malocclusion in Himachali population.

Materials and methods: 90 subjects divided into three groups $(n=30$ each) on the basis of Angle's classification. Palatal rugae were marked on dental casts and evaluated for length, pattern and orientation. Obtained measurements were then statistically analysed.

Conclusion: Primary palatal rugae's length was found more in Class II followed by Class III and Class I malocclusion. Among the pattern of the primary palatal rugae, curved pattern were more evident on both right and left sides of all malocclusion groups. Horizontal directed orientation is more predominant on the right side and posteriorly directed on the left side of the first primary palatine rugae.
\end{abstract}

Keywords: Rugae, Malocclusion, orientation pattern, length, morphology

\section{INTRODUCTION}

Rugae are derived from Greek word means seam. It describes the intersection in a tissue or organ between two separate parts when they are embryologically separated from each other. Rugae or plica palatine or transverse ridge folds are the anatomical folds located on the anterior palate behind the incisive papillae. It is used in various branches of medical world such as determination of sex of an individual, orthodontics and forensic odontology. ${ }^{1}$ These transverse ridges present on both the sides of the mid-palatal raphe behind the incisive papillae. ${ }^{2}$ The classification of rugae includes shape, length, number and identification pattern. $^{3}$ The clinical implications of palatal rugae in orthodontics includes its use in evaluation of the dental movements and as landmark in various treatment modalities in orthodontics. They can also be used for the identification of submucosal clefts and for the assessment of the amount of anteroposterior tooth movement after orthodontic treatment. Moreover, they are used as a landmark in the superimposition of dental casts for orthodontic purpose as it is a stable point. ${ }^{4,5}$ Teeth and palatine ridges have been linked as both form during similar time of intrauterine life. Therefore, palatine ridges serve as stable landmark and \& play significant role in clinical orthodontics. ${ }^{6,7}$ Researchers have evaluated difference in palatal rugae pattern in different population but few studies have been conducted to evaluate the association of rugae pattern with dental malocclusion. Hence, the aims and objectives of our study is to investigate that if there is any association of morphological characteristics of palatal 
rugae with dental malocclusion in Himachali population.

\section{MATERIALS AND METHODS}

The subjects were selected from the patients visiting the department seeking for orthodontic treatment. The inclusion criteria of the study were selected as age of 12-30 years, full permanent dentition, wellestablished molar and incisor relationship. Subjects with quarter or half-cusp molar relation, subdivision and asymmetric cases, complex cases with unmatched molar and incisor relations, patients with history of extraction or previous orthodontic treatment, cleft lip and palate, craniofacial \& dental anomalies, pathology or trauma involving the head and neck region, habits such as tongue thrusting or thumb sucking and carious or missing molars and incisors were excluded from the study.

The sample $(n=90)$ was divided into three equal groups with 30 subjects in each group. The subjects were categorized on the basis of Angle's classification of molar relationship (i.e. Class I, Class II and Class III)

\section{Methodology}

Study was conducted on the pretreatment dental stone models obtained from the alginate impressions of upper dental arch. The palatal rugae were outlined with a sharp HB pencil. The most medial and distal ends of the palatal rugae were marked on dental cast and linear distances were measured using digital vernier calipers accuracy upto $0.01 \mathrm{~mm}$ (Fig 1).

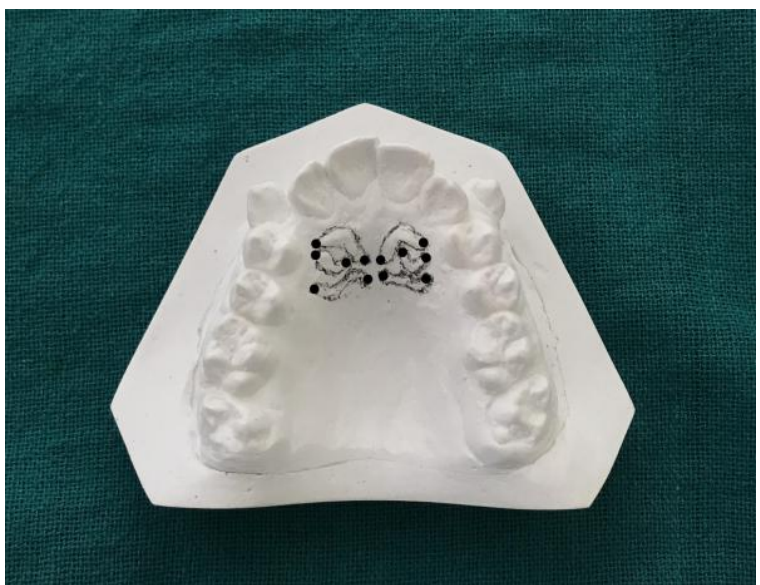

Figure1: Tracings of palatal rugae on dental cast.

The features of palatal rugae were assessed initially on the basis of length of palatal rugae. Then, based on length, the rugae were categorized as primary (> 5 $\mathrm{mm})$, secondary (3-5 $\mathrm{mm})$ and fragmentary type $(<3 \mathrm{~mm})$. The total number of rugae was recorded for both right and left sides. The three anterior-most primary rugae (labelled as rugae 1,2 and 3) were observed for the length, pattern and orientation. The assessment of pattern and orientation was classified according to the method described by Hauser et al (Figs 2 and 3).

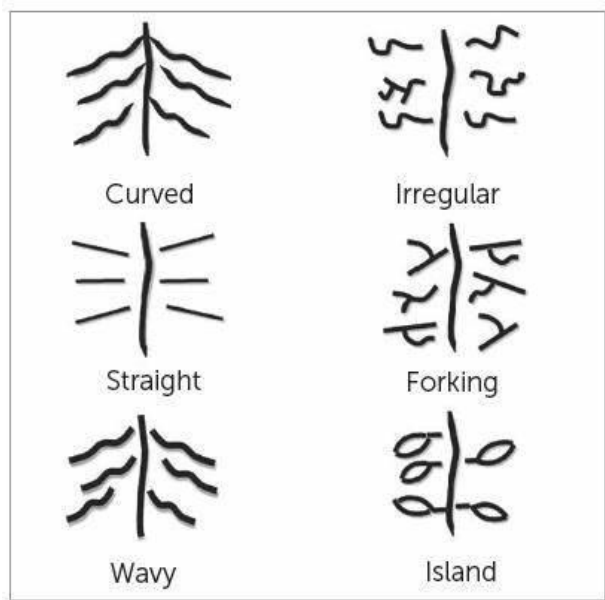

Fig 2: Patterns of palatal rugae

\section{Statistical analysis}

After obtaining the measurements, data were analysed using statistical analysis

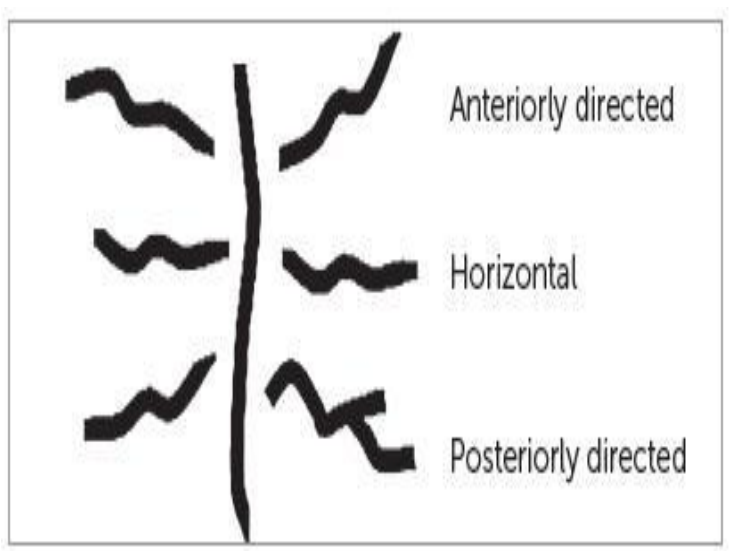

Fig 3: Orientation of palatal rugae

(SPSS version 21) Descriptive statistics for the palatal rugae lengths, i.e. means and standard deviations (SD) were calculated. 
Indu Dhiman et.al. Evaluation of association between morphological characteristics of palatal rugaewith different malocclusions in Himachali population

The pattern and orientation were compared across the three groups using the Chi-square test.

\section{Method error}

To rule out any error in measurement, 30 dental casts were reevaluated by the main investigator using intraclass correlation. Intra class correlation coefficient was found to be $>0.75$ and kappa statistics was found to be $0.80-1.00$, both showed the perfect agreement for the assessment of reliability of measurements. A p-value $\leq 0.05$ was considered as statistically significant.

\section{RESULTS}

Table I: Number of Palatal Rugae among the Malocclusion Groups

\begin{tabular}{|c|c|c|c|c|c|}
\hline Number of rugae & & Class I & Class II & Class III & P value \\
\hline Primary & Right & $4.10 \pm 1.5$ & $2.78 \pm 1.2$ & $3.91 \pm 0.5$ & $0.04^{*}$ \\
\cline { 2 - 6 } & Left & $4.22 \pm 1.5$ & $2.67 \pm 0.7$ & $3.97 \pm 0.6$ & $0.01^{*}$ \\
\hline \multirow{2}{*}{ Secondary } & Right & $1.15 \pm 0.5$ & $1.25 \pm 0.9$ & $1.01 \pm 0.7$ & $0.001^{* *}$ \\
\cline { 2 - 6 } & left & $1.42 \pm 0.7$ & $1.04 \pm 0.6$ & $0.95 \pm 0.7$ & $0.03^{*}$ \\
\hline Fragmentary & Right & $0.18 \pm 0.3$ & $0.37 \pm 0.5$ & $0.46 \pm 0.8$ & $0.02^{*}$ \\
\cline { 2 - 6 } & left & $0.31 \pm 0.4$ & $0.48 \pm 0.3$ & $0.50 \pm 0.7$ & $0.01^{*}$ \\
\hline
\end{tabular}

Table II: Lenghts of Palatal Rugae among Malooclusion Groups

\begin{tabular}{|c|c|c|c|c|c|}
\hline Length of primary rugae & & Class I & Class II & Class III & p value \\
\hline First & Right & $7.63 \pm 1.33$ & $7.90 \pm 1.33$ & $6.41 \pm 1.13$ & 0.24 \\
\hline & Left & $7.73 \pm 1.14$ & $8.26 \pm 1.21$ & $7.23 \pm 1.35$ & $0.04^{*}$ \\
\hline Second & Right & $6.93 \pm 1.33$ & $8.90 \pm 1.50$ & $8.20 \pm 1.65$ & 0.63 \\
\hline Third & left & $9.53 \pm 1.59$ & $8.66 \pm 1.88$ & $6.96 \pm 1.58$ & 0.08 \\
\hline & Right & $7.06 \pm 1.99$ & $9.26 \pm 1.67$ & $9.06 \pm 0.70$ & $0.02^{*}$ \\
\hline & left & $6.90 \pm 0.70$ & $9.23 \pm 1.70$ & $9.03 \pm 0.70$ & $0.004^{*}$ \\
\hline
\end{tabular}

Table III: Pattern of Primary Palatal Rugae Comparison among Different Mlocclusion Groups

\begin{tabular}{|c|c|c|c|c|c|c|}
\hline \multicolumn{3}{|c|}{ PATTERNS OF PRIMARY RUGAE } & \multirow{2}{*}{$\begin{array}{c}\text { CLASS I } \\
20\end{array}$} & \multirow{2}{*}{$\frac{\text { CLASS II }}{17}$} & \multirow{2}{*}{$\frac{\text { CLASS III }}{18}$} & \multirow{2}{*}{$\frac{\text { p VALUE }}{0.005^{*}}$} \\
\hline First & \multirow[t]{6}{*}{ Right } & Curved & & & & \\
\hline & & Straight & 8 & 9 & 7 & \\
\hline & & Wavy & 1 & 2 & 2 & \\
\hline & & Irregular & 0 & 1 & 1 & \\
\hline & & Forking & 1 & 1 & 1 & \\
\hline & & Island & 0 & 0 & 1 & \\
\hline & \multirow[t]{6}{*}{ Left } & Curved & 22 & 18 & 20 & $0.006^{*}$ \\
\hline & & Straight & 7 & 8 & 3 & \\
\hline & & Wavy & 0 & 1 & 4 & \\
\hline & & Irregular & 0 & 1 & 1 & \\
\hline & & Forking & 1 & 1 & 1 & \\
\hline & & Island & 0 & 1 & 1 & \\
\hline \multirow[t]{12}{*}{ Second } & \multirow[t]{6}{*}{ Right } & Curved & 18 & 17 & 20 & $0.004 *$ \\
\hline & & Straight & 1 & 2 & 1 & \\
\hline & & Wavy & 5 & 6 & 4 & \\
\hline & & Irregular & 1 & 2 & 2 & \\
\hline & & Forking & 4 & 2 & 1 & \\
\hline & & Island & 1 & 1 & 2 & \\
\hline & \multirow[t]{6}{*}{ Left } & Curved & 16 & 14 & 19 & $0.002 *$ \\
\hline & & Straight & 0 & 3 & 3 & \\
\hline & & Wavy & 5 & 8 & 4 & \\
\hline & & Irregular & 1 & 1 & 2 & \\
\hline & & Forking & 8 & 4 & 2 & \\
\hline & & Island & 0 & 0 & 0 & \\
\hline \multirow[t]{12}{*}{ Third } & \multirow[t]{6}{*}{ Right } & Curved & 16 & 17 & 15 & $0.04 *$ \\
\hline & & Straight & 3 & 1 & 3 & \\
\hline & & Wavy & 7 & 11 & 6 & \\
\hline & & Irregular & 0 & 0 & 2 & \\
\hline & & Forking & 4 & 1 & 2 & \\
\hline & & Island & 0 & 0 & 2 & \\
\hline & \multirow[t]{6}{*}{ Left } & Curved & 15 & 14 & 16 & $0.02 *$ \\
\hline & & Straight & 2 & 3 & 2 & \\
\hline & & Wavy & 11 & 10 & 6 & \\
\hline & & Irregular & 0 & 1 & 2 & \\
\hline & & Forking & 2 & 2 & 2 & \\
\hline & & Island & 0 & 0 & 2 & \\
\hline
\end{tabular}


Indu Dhiman et.al. Evaluation of association between morphological characteristics of palatal rugaewith different malocclusions in Himachali population

Table IV: Orientation of Primary Palatal Rugae Comparison among Malocclusion Groups \begin{tabular}{|l|l|l|l|l|c|}
\hline ORIENTATION OF PRIMARY RUGAE & CLASS I & CLASS II & CLASS III & p VALUE \\
\hline
\end{tabular}

\begin{tabular}{|c|c|c|c|c|c|c|}
\hline \multirow{6}{*}{ First } & \multirow{3}{*}{ Right } & Posteriorly directed & 6 & 11 & 7 & 0.10 \\
\hline & & Horizontal & 17 & 6 & 20 & \\
\hline & & Anteriorly directed & 7 & 3 & 3 & \\
\hline & \multirow[t]{3}{*}{ Left } & Posteriorly directed & 17 & 13 & 20 & $0.00 \mathrm{p} 3 *$ \\
\hline & & Horizontal & 5 & 11 & 6 & \\
\hline & & Anteriorly directed & 8 & 6 & 4 & \\
\hline \multirow[t]{6}{*}{ Second } & \multirow[t]{3}{*}{ Right } & Posteriorly directed & 6 & 9 & 4 & 0.12 \\
\hline & & Horizontal & 2 & 6 & 6 & \\
\hline & & Anteriorly directed & 21 & 15 & 20 & \\
\hline & \multirow[t]{3}{*}{ Left } & Posteriorly directed & 14 & 15 & 21 & $0.005 *$ \\
\hline & & Horizontal & 5 & 5 & 4 & \\
\hline & & Anteriorly directed & 11 & 10 & 5 & \\
\hline \multirow[t]{6}{*}{ Third } & \multirow[t]{3}{*}{ Right } & Posteriorly directed & 9 & 8 & 4 & 0.14 \\
\hline & & Horizontal & 4 & 4 & 5 & \\
\hline & & Anteriorly directed & 17 & 18 & 21 & \\
\hline & \multirow[t]{3}{*}{ Left } & Posteriorly directed & 18 & 13 & 20 & $0.01 *$ \\
\hline & & Horizontal & 2 & 9 & 4 & \\
\hline & & Anteriorly directed & 10 & 8 & 6 & \\
\hline
\end{tabular}

Descriptive statistics for the number of palatal rugae among the malocclusion groups were calculated and compared using ANOVA and statistically significant difference was found among various malocclusion groups as shown in Table I. The length of the palatal rugae among the malocclusion groups was compared and statistically significant difference was found on left side of first primary rugae and on both sides of third primary rugae as shown in Table II. The pattern and orientation of primary palatal rugae were compared using Chi square as shown in Table III and IV.

\section{DISCUSSION}

Permanent ridges present on the anterior one third of the hard palate commonly known as palatine rugae. These rugae possess unique characteristics specific to particular individual which are helpful in forensic identification. Due to the unique and stable characteristics of plica palatina, they can be used as a reliable marker for orthodontic treatment. Various studies in the literature have made an attempt to establish the association of palatine rugae pattern with various malocclusions specific to their ethnic population. As the data available for a particular population can not be applied to other population due to its morphologic characteristics, so the purpose of our study is to evaluate the association of palatal rugae characteristics and various Angle's classes of malocclusion in Himachali population.

The result of the present study showed that the mean value of number of primary and fragmentary palatatine rugae was found to be greatest in Class I malocclusion on both right and left side as compare to Class II and class III malocclusion and was statistically significant as $p$ value $<0.05$ as shown in Table I. This can be explained on the basis of the results reported by Patil et $\mathrm{al}^{1}$ (2008) and Lysell et $\mathrm{al}^{9}$ (1955) and suggested that the role of palatine rugae in various functions of stomatognathic system such as mastication, deglutition and speech. Moreover, the dorsal surface of the tongue is invariably related with the rugae pattern. Tongue position vary with the different classes of malocclusion so, the pattern of rugae also as explained by the study done by Primozic et $\mathrm{al}^{10}(2013)$ and Yilmaz et $\mathrm{al}^{11}$ (2011).

Further the result of the present study showed significant differences in the pattern of rugae among the various groups used in the study as shown in Table I. This was in accordance to the study done by Farheen et $\mathrm{al}^{12}$ (2018) in contrary to the results reported by Kapoor et $\mathrm{al}^{13}$. This might be because of difference in sample size and ethnicity of population.

Moreover the mean number of rugae were found to be highest on the right side as compared to the left side when compared 
among the three malocclusion groups as shown in table I this can be explained on the basis of the study done by Dhoke and Osato $^{14}$ (1994) and Kapali et al ${ }^{15}$ (1997) who stated that regression evolution phenomenon that dominates the right side of the palate mainly pertaining to the secondary rugae. On the contrary the study done by Crystal et al (2020), their results varies may be due to the exclusion of the secondary rugae and also due to difference in the ethnicity of the population.

The results of our study showed that the mean lengths of palatal rugae was found to be greatest in Class I malocclusion as compared to Class II and Class III malocclusion. This is in accordance to the study done by Farheen et $\mathrm{al}^{12}$ (2018) who concluded similar findings. On the contrary the study done by Kapoor et $\mathrm{al}^{13}$ reported that highest length in the Angles class II malocclusion. The difference in the results may be attributed to the sample size and ethnic variations.

\section{CONCLUSION}

The present study showed that there is an association present between the length, pattern and orientation of rugae with the Angle's classes of malocclusion:

- All types of rugae were significantly distributed more on the right side as compared to left side on the palate.

- Length of the primary palatal rugae was found more in Class II followed by Class III and Class I malocclusion.

- Among the pattern of the primary palatal rugae, curved pattern were more evident on both right and left sides of all malocclusion groups.

- Horizontal directed orientation is more predominant on the right side and posteriorly directed on the left side of the first primary palatine rugae whereas anteriorly and posteriorly directed orientation is more predominant on the right side and left side respectively in second and third primary palatine rugae among different malocclusion groups.

\section{Source(s) of support: Self}

\section{Presentation at a meeting: None}

\section{Conflicting Interest: None}

\section{Ethical Approval: Approved}

\section{REFERENCES}

1. Patil MS, Patil SB, Acharya AB. Palatine rugae and their significance in clinical dentistry: a review of the literature. J Am Dent Assoc 2008 Nov;139(11):1471-8

2. Hausser E.The palatal ridges in man; their significances and their modifications. Stoma (Heidelb). 1951 Feb; 4(1):3-26.

3. Shukla D, Chowdhary A, BablaniA, Jain $\mathrm{P}$ and Thapar R. Establishing the reliability of palatal rugae pattern in individual identification (following orthodontic treatment). J Forensic Odontostomatol 2011 Jul 1; 29(1):20-9.

4. Bailey LT, Esmailnejad A, Almeida MA. Stability of the palatal rugae as landmarks for analysis of dental casts in extraction and nonextraction cases. Angle Orthod 1996; 66(1):73-8.

5. Abdol Aziz HM, Sabot EN. Palatal rugae area: A landmark for analysis of pre- and post-orthodontically treated adult Egyptian patients. La revue de santé de la Méditerranéeorientale 2001; 7(1-2):60-6.

6. DeepakV, MalgaonkarNI, ShahNK, Nasser AS, Dagrus K, Bassle T. Palatal rugae patterns in orthodontically treated cases, are they a reliable forensic marker? J Int Oral Health 2014 Sep;6(5):89-95.

7. Ali B, Shaikh A, Fida M. Stability of Palatal Rugae as a Forensic Marker in Orthodontically Treated Cases.J Forensic Sci 2016 Sep; 61(5):1351-5.

8. Barbo BN, Azeredo F, and Menezes LM. Assessment of Size, Shape, and Position of Palatal Rugae: A Preliminary Study. Menezes LM et al. Oral Health and Dental Studies. 2018,1(1):3.

9. Lysell L. Plicae palatinaetransversae and papilla incisive in man: a morphologic and genetic study. ActaOdontol Scand. 1955; 13(Suppl 18):5-137.

10. J. Primozic, G. Perinetti, S. Richmond, M. Ovsenik. Three-dimensional longitudinal evaluation of palatal vault changes in 
Indu Dhiman et.al. Evaluation of association between morphological characteristics of palatal rugaewith different malocclusions in Himachali population

growing subjects. Angle Orthod, Vol. 82, no. 4, 2012, pp. 632-6.

11. Yilmaz F, Sagdiç D, Karaçay S, Akin E, Bulakbasi N. Tongue movements in patients with skeletal Class II malocclusion evaluated with real-time balanced turbo field echo cine magnetic resonance imaging. Am J OrthodDentofacialOrthop. 2011 May; 139(5):e415-25.

12. Fatima F, Fida M, Shaikh A. The association between palatal rugae pattern and dental malocclusion.Dental Press $\mathbf{J}$ Orthod. 2019 Jan-Feb; 24(1):37.e1-9.

13. Kapoor P, Miglani R (2015) Transverse changes in lateral and medial aspects of palatal rugae after mid palatal expansion: A pilot study. J Forensic Dent Sci 7(1): 8-13.

14. Dhoke M, Osato S. Morphological study of the palatal rugae in Japanese. Bilateral difference in the regressive evolution of the palatal rugae.J Oral Biol. 1994; 36:126-40.
15. Kapali S, Townsend G, Richards L, Parish T. Palatal rugae patterns in Australian aborigines and Caucasians. Aust Dent J. 1997 Apr;42(2):129-33.

16. Soans RC, Mohammed A, Murali PS, Mendonca M, Shetty P, Kumari V. Morphology of Palatal Rugae in Various Sagittal Skeletal Malocclusions in Kerala Population- A Retrospective Study. Indian Journal of Forensic Medicine \& Toxicology, April-June 2020, Vol. 14, No.2.s.

How to cite this article: Dhiman I, Thakur S, Singh DP et.al. Association of morphological characteristics of palatal rugae pattern with dental malocclusion in Himachal population. International Journal of Research and Review. 2021; 8(5): 13-18. DOI: https://doi.org/ 10.52403/ijrr.20210503 